\title{
A method to characterize the different extreme waves for islands exposed to various wave regimes: a case study devoted to Reunion Island
}

\author{
S. Lecacheux ${ }^{1}$, R. Pedreros ${ }^{1}$, G. Le Cozannet ${ }^{1}$, J. Thiébot ${ }^{2}$, Y. De La Torre ${ }^{1}$, and T. Bulteau ${ }^{1}$ \\ ${ }^{1}$ BRGM, 3 Avenue Claude Guillemin Cedex 2, BP 6009, 45060 Orléans, France \\ ${ }^{2}$ LUSAC, Université de Caen Basse-Normandie, site universitaire, 50130 Cherbourg, France \\ Correspondence to: S. Lecacheux (s.lecacheux@brgm.fr)
}

Received: 26 July 2011 - Revised: 29 March 2012 - Accepted: 16 April 2012 - Published: 31 July 2012

\begin{abstract}
This paper outlines a new approach devoted to the analysis of extreme waves in presence of several wave regimes. It entails discriminating the different wave regimes from offshore wave data using classification algorithms, before conducting the extreme wave analysis for each regime separately. The concept is applied to the pilot site of Reunion Island which is affected by three main wave regimes: southern waves, trade-wind waves and cyclonic waves. Several extreme wave scenarios are determined for each regime, based on real historical cases (for cyclonic waves) and extreme value analysis (for non-cyclonic waves). For each scenario, the nearshore wave characteristics are modelled all around Reunion Island and the linear theory equations are used to back calculate the equivalent deep-water wave characteristics for each portion of the coast. The relative exposure of the coastline to the extreme waves of each regime is determined by comparing the equivalent deep-water wave characteristics.

This method provides a practical framework to perform an analysis of extremes within a complex environment presenting several sources of extreme waves. First, at a particular coastal location, it allows for inter-comparison between various kinds of extreme waves that are generated by different processes and that may occur at different periods of the year. Then, it enables us to analyse the alongshore variability in wave exposition, which is a good indicator of potential runup extreme values. For the case of Reunion Island, cyclonic waves are dominant offshore around the island, with equivalent deep-water wave heights up to $18 \mathrm{~m}$ for the northern part. Nevertheless, due to nearshore wave refraction, southern waves may become as energetic as cyclonic waves on
\end{abstract}

the western part of the island and induce similar impacts in terms of runup and submersion. This method can be easily transposed to other case studies and can be adapted, depending on the data availability.

\section{Introduction}

The determination of coastal hazards maps at a regional scale is of prime importance in implementing efficient coastal risk reduction programs and in achieving proper management of urban development. This is especially crucial for islands where the living space is limited and where populations are often concentrated near the coastline.

Waves play a crucial role in coastal erosion and marine inundation hazards. In shallow waters, the breaking of waves causes a local elevation of the mean water level, called wave setup, and the maximum vertical extent of wave uprush on a beach or structure above the mean water level is termed runup. A reliable assessment of extreme runup values is necessary to map coastal hazards, especially for inundation and overtopping (Ruggiero et al., 2001). At regional scales, the runup is usually calculated with empirical formulas, such as Stockdon et al. (2006), using deep-water wave input and assuming a shore-normal orientation. In practice, the runup amplitude also depends on the wave incidence angle and the nearshore wave transformation due to the local bathymetry (by refraction, reflection, diffraction and bottom friction). Thus, even at regional scale, the determination of extreme wave characteristics must be site-specific. 
In coastal engineering, two classic approaches may be used to determine local extreme wave characteristics. The first approach entails performing a statistical analysis directly at a nearshore point in front of the area of interest, as in Lee and Jun (2006). Waves are then usually considered as fully refracted and normal to the shore. The feasibility of this approach depends on the existence of long-term coastal wave measurements or numerical simulations, which are rarely available at the regional scale. In the second approach, offshore design wave heights are first determined for different types of waves, corresponding to angular sectors (for example, every $30^{\circ}$ ) or seasons (winter waves, etc.). Then, they are propagated using a nearshore wave transformation model to calculate the local shore-normal wave characteristics related to each type (Vitousek and Fletcher, 2008; Vitousek et al., 2008; Panigrahi and Misra, 2010). In any case, a prerequisite to the calculation of runup with empirical formulas from nearshore wave characteristics is the determination of "equivalent deep-water wave heights" noted $H_{0 \_ \text {eq }}$ in the following. Traditionally, $H_{0 \_ \text {eq }}$ is a hypothetical wave height devised to adjust the deep-water wave height $\left(H_{0}\right)$ that may have undergone nearshore transformations such as wave refraction (Goda, 2000). Here, it is defined, like in Stockdon et al. (2006), as the nearshore wave height $H_{\mathrm{s}}$ (refracted and dissipated over local bathymetry in the model) that has been reverse shoaled to back calculate the corresponding deepwater wave height. Thus, the "equivalent deep-water waves" facilitates the inter-comparison of extreme waves between different sites and can be used in the runup parameterizations taking into account offshore wave characteristics.

In this study, we intend to compare the relative contribution of several types of wave regime (trade-wind waves, cyclonic waves and southern waves) to the local wave extreme values around tropical islands. Thus, we propose an adjustment of the second approach, which entails calculating deep-water wave statistics before modelling the corresponding coastal wave characteristics. The method is applied for Reunion Island.

First, a new approach devoted to the analysis of extreme waves in the presence of several wave regimes is presented. To satisfy data homogeneity requirements, each wave regime must be studied separately. Although a directional criterion is often adopted in the literature (Mathiesen et al., 1994; Morton et al., 1997; Menendez et al., 2009; Mackay et al., 2010), using a single criterion is not always sufficient to distinguish homogenous wave groups. Our approach entails (1) identifying homogeneous groups of waves using a classification algorithm, (2) performing an extreme wave analysis for each group and (3) building several wave-event scenarios from the wave statistics for each regime.

Then, for each scenario, local wave characteristics are computed all around the island by means of a nearshore wave transformation model. The exposure of each of the island's coastlines to the different extreme events is determined by comparing the "equivalent deep-water waves" calculated for

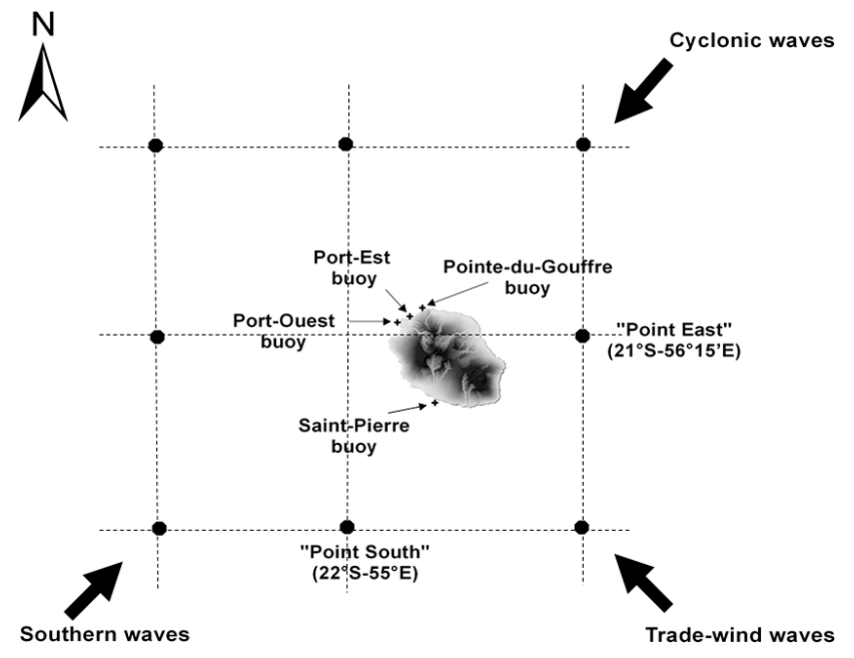

Fig. 1. The pilot site and positions of the wave gauges and the NWW3 points used in the study. The arrows indicate the sources of the dominant wave regimes.

each regime. As the magnitude of the wave runup depends on the amount of energy carried out by the waves, the comparison is based on both wave height and energy.

This paper is organized as follows. Section 2 introduces the pilot site as well as the data. In Sect. 3, the method is fully described. Section 4 presents the results, Sect. 5 is devoted to the discussion and Sect. 6 to the conclusion.

\section{Pilot site and data}

\subsection{Reunion Island and the main wave regimes}

Reunion Island is a French Overseas Department lying east of Madagascar. It is a volcanic island with a volcanic body in the northeast (the massif of the Piton des Neiges), which has been inactive for $12000 \mathrm{yr}$, and an active portion in the southeast (the Piton de la Fournaise). Due to the mountainous nature of the island's interior, $80 \%$ of the population is concentrated near the shore, thereby resulting in intense anthropic pressures. Coastal defence against erosion and marine submersion is a major issue in this area. The island is exposed to three dominant wave regimes, as illustrated in Fig. 1: trade-wind waves, southern waves and cyclonic waves. Cazes-Duvat and Paskoff (2004) describe these wave regimes as follows.

Trade-wind waves arrive mainly from the east and southeast, and their heights barely exceed $2 \mathrm{~m}$, with periods ranging between 5 and $10 \mathrm{~s}$. They are generated by trade winds in the inter-tropical zone and are especially energetic during the Southern Hemisphere winter, with exceptional wave heights around $5 \mathrm{~m}$. Southern waves come from the southwest, with a mean height of about 3-4 m and periods between 10 and $20 \mathrm{~s}$. They are generated at great distances from Reunion 
Island by storms in the Southern Hemisphere's temperate zone. Cyclonic waves are the most energetic events and occur only a few days a year between November and March. Cyclones usually come from the northeast and then continue their course either north of the island or, less frequently, to the south. Cyclonic waves mainly impact the island's northern and eastern parts.

\subsection{Data}

Two different types of wave data were used. For non-cyclonic wave analysis (trade-wind waves and southern waves), longterm time series of wave parameters were extracted from the NOAA Wavewatch3 re-analysis (hereinafter called NWW3), covering a 13-yr period between 1997 and 2009 (Tolman, 2002). The data have a spatial resolution of $1.25^{\circ}$ in longitude and $1^{\circ}$ in latitude, and a temporal resolution of three hours. This choice was motivated by the quality of the NWW3 dataset in terms of extremes. Indeed, other re-analyses, such as ERA-40, provide longer time series, but the extremes are not as well reproduced (Caires et al., 2004). Two points near Reunion Island were used (see Fig. 1): "Point South" $\left(22^{\circ} \mathrm{S}-55^{\circ} \mathrm{E}\right)$ for the southern wave analysis and "Point East" $\left(21^{\circ} \mathrm{S}-56^{\circ} 15^{\prime} \mathrm{E}\right)$ for the trade-wind wave analysis. For the cyclonic wave analysis, information about historical cyclones was drawn from the best track dataset from 1932 to 2008 provided by Méteo-France (the French Meteorological Service).

For the numerical modelling of waves, the bathymetric data were taken from the global international database SRTM30_PLUS DEM (Becker et al., 2009), gridded at about $1 \mathrm{~km}$ in latitude and longitude, and the bathymetric sounds from the SHOM (French Naval Hydrographic and Oceanographic Service) data, with a maximum resolution of $25 \mathrm{~m}$ in coastal areas. Four coastal wave gauges, shown in Fig. 1, were used for the validation of wave modelling: "Port Est" at a depth of $27 \mathrm{~m}$ (period of measurement: November 1996 to present), "Pointe du Gouffre" at a depth of $31 \mathrm{~m}$ (period of measurement: May 2000 to present), "Port Ouest" at a depth of $25 \mathrm{~m}$ (period of measurement: February 1997 to today) and "Saint Pierre" at a depth of $33 \mathrm{~m}$ (period of measurement: September 2000 to November 2010).

\section{The overall method}

The method entails three main steps, summarized in the flow chart in Fig. 2.

Firstly, several extreme wave event scenarios were determined for each wave regime separately. For southern and trade-wind waves (Sect. 3.1), a probabilistic approach was chosen based on an analysis of NWW3 data for two points near Reunion Island. The wave regimes were first identified with classification algorithms, and an extreme value analysis led to the determination of the 50-yr significant wave

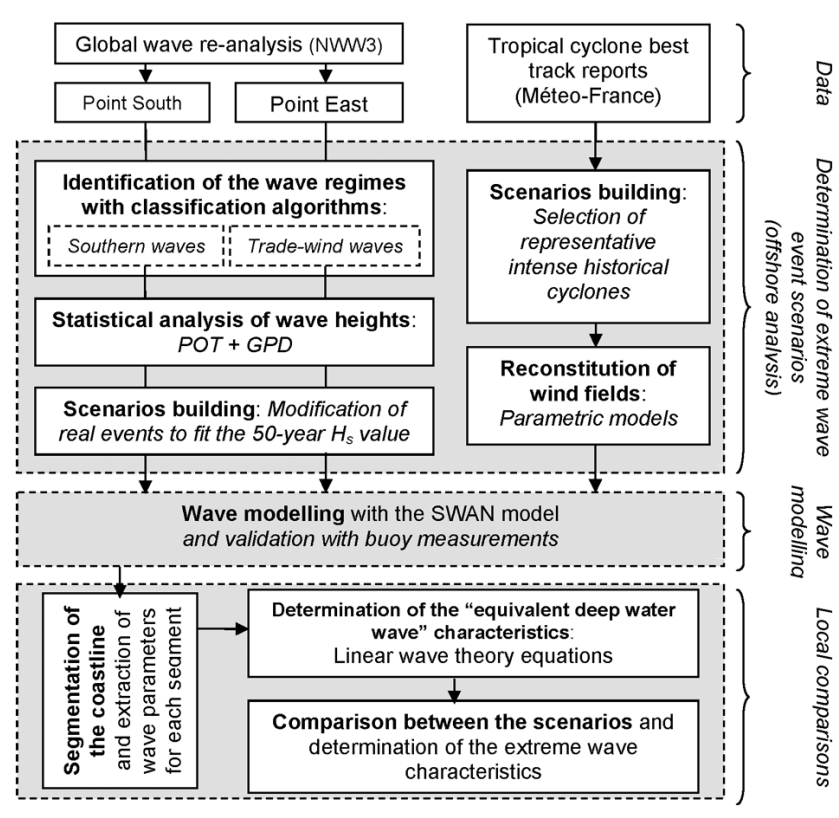

Fig. 2. Diagram of the overall method.

height $\left(H_{\mathrm{s}}\right)$. The scenarios were based on historical cases that had been modified to fit the $50-\mathrm{yr} H_{\mathrm{s}}$. For cyclonic waves (Sect. 3.2), global re-analysis usually under-estimates wave heights because their spatial and temporal resolutions are too coarse. Thus, long-term cyclonic wave data are not available to implement a probabilistic approach. We therefore chose to use a deterministic approach where the scenarios correspond to actual historical cases.

Secondly, for each scenario, the nearshore wave fields were simulated with the SWAN model (Booij et al., 1999) until $100 \mathrm{~m}$ resolution grids surrounding the island (Sect. 3.3).

Finally, Reunion Island was divided into coastal segments of uniform orientation. For each segment and each scenario, the wave characteristics were extracted at a nearshore location and the "equivalent deep-water wave heights" were computed. The inter-comparison between the "equivalent deepwater wave characteristics" led to the determination of the relative exposure of each segment to the extreme waves from each regime (Sect. 3.4).

\subsection{Determination of extreme wave scenarios for non-cyclonic waves}

\subsubsection{Identification of the wave regimes}

As explained in Sect. 1, an assessment of extreme values must be based on a homogeneous set of independent events. Classification algorithms (Butel et al., 2002) can be used to separate the different wave regimes from the NWW3 time series into a limited number of sea states. 


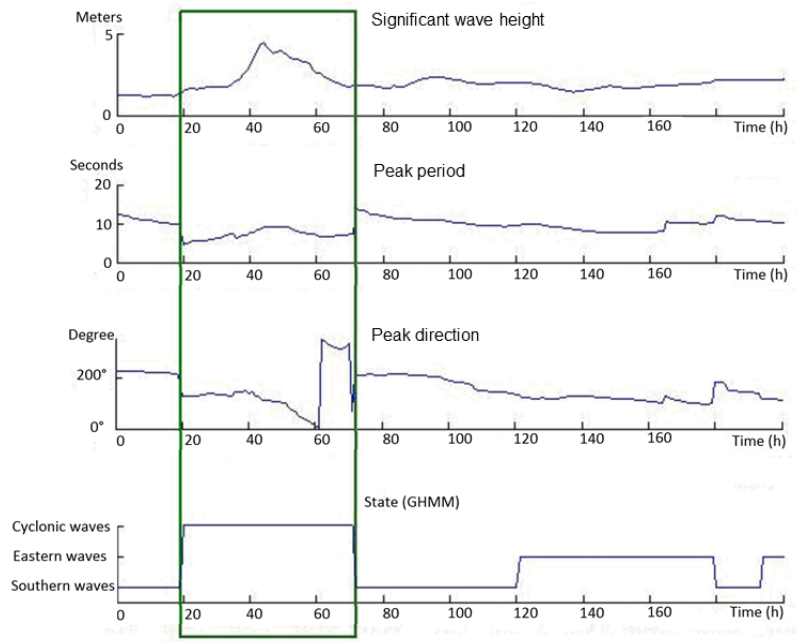

Fig. 3. Example of the automatic identification of cyclone Dina at "Point East" using the GHMM algorithm: The storm's effects are recognized due to the high temporal variability of the waves' significant heights and directions.

At "Point South", southern waves were isolated from the NWW3 time series using a k-means clustering algorithm that classifies the wave's parameters $\left\{H_{\mathrm{s}}(t) \cdot \cos \left(D_{\mathrm{p}}(t)\right), H_{\mathrm{s}}(t) \cdot \sin \left(D_{\mathrm{p}}(t)\right), T_{\mathrm{p}}(t)\right\}, \quad$ following the same approach as Butel et al. (2002) and Le Cozannet et al. (2011). Here, the distance between two triplets is calculated as follows:

$d\left\langle\begin{array}{cc}H_{\mathrm{s}_{i}} & H_{\mathrm{s}_{j}} \\ T_{\mathrm{p}_{i}} & T_{\mathrm{p}_{j}} \\ D_{\mathrm{p}_{i}} & D_{\mathrm{p}_{j}}\end{array}\right\rangle$
$=\sqrt{\left(\frac{H_{\mathrm{s}_{i}} \cdot \cos \left(D_{\mathrm{p}_{i}}\right)-H_{\mathrm{s}_{j}} \cdot \cos \left(D_{\mathrm{p}_{j}}\right)}{\sigma_{H_{\mathrm{s}}} \cos \left(D_{\mathrm{p}}\right)}\right)^{2}+\left(\frac{H_{\mathrm{s}_{i}} \cdot \sin \left(D_{\mathrm{p}_{i}}\right)-H_{\mathrm{s}_{j}} \cdot \sin \left(D_{\mathrm{p}_{j}}\right)}{\sigma_{H_{\mathrm{s}}} \sin \left(D_{\mathrm{p}}\right)}\right)^{2}+\left(\frac{T_{\mathrm{p}_{i}}-T_{\mathrm{p}_{j}}}{\sigma_{T_{\mathrm{p}}}}\right)^{2}}$

with $H_{\mathrm{s}}$, the significant wave height, $T_{\mathrm{p}}$, the peak period and $D_{\mathrm{p}}$, the peak direction. The identification of the wave regimes among the different classes is based on the barycentre value and a seasonal criterion.

Isolating trade-wind wave regimes for "Point East" was more difficult because these waves may have the same direction, period and height as cyclonic waves in the NWW3 model. This is partly due to the limitations of NWW3 in modelling cyclonic waves. Thus, the classification algorithm is not able to distinguish the trade-wind waves effectively from the cyclonic waves. Fortunately, while the trade-wind waves remain relatively stationary, cyclonic waves, and particularly their direction, vary quickly. Thus, we used a semi-automatic classification process in which the temporal variability of the wave's parameters is taken into account. In practice, the wave signal $\left\{H_{\mathrm{s}}(t) \cdot \cos \left(D_{\mathrm{p}}(t)\right), H_{\mathrm{s}}(t) \cdot \sin \left(D_{\mathrm{p}}(t)\right), T_{\mathrm{p}}(t)\right\}$ is modelled as a Gaussian hidden state Markov model chain (GHMM) using the METIS toolbox (Monbet and Ailliot, 2005). This statistical model is adjusted using an expectation-maximization algorithm. After this process, trade-wind waves were classified in a hidden state characterized by eastern waves with low variance of the wave parameters. This method enabled the identification and exclusion of most of the cyclones from the NWW3 time series at "Point East", as illustrated in Fig. 3. The few remaining classification errors were corrected manually. Results of the GHMM classification at "Point East" are presented in Table 1 . They have been checked visually to ensure that cyclonic events have been effectively separated from the tradewind waves in the resulting modes. This second algorithm avoids the labour-intensive task of manually removing the cyclonic waves from the NWW3 time series. However, in practice, it is very sensitive to the initial conditions input to the algorithm and is thus not straightforward to implement. Therefore, it should be used only when the k-means clustering algorithm is unable to discriminate waves into independent modes.

\subsubsection{Statistical analysis of wave heights}

The classification process described in Sect. 3.1.1 resulted in homogeneous groups of wave data: We chose one group for southern waves at "Point South" and one group for tradewind waves at "Point East". For each group, an extreme analysis was performed on $H_{\mathrm{s}}$ using the WAFO toolbox (Brodtkorb et al., 2000). It consists firstly in identifying independent extreme wave data using the Peak Over Threshold (POT) method. Next, GPD (General Pareto Distribution) laws were fitted to the data. The three parameters of each law were fitted using the maximum likelihood, the method of moments and the probability weighted moment method. Lastly, the validity of the fit was evaluated with KolmogorovSmirnov and khi-2 tests. For our purposes, the best fit was obtained using a GPD with coefficients calculated using the maximum likelihood. Results are presented in Fig. 4. Considering the length of the time series, the maximum return period was set to $50 \mathrm{yr}$.

\subsubsection{Scenario building}

The statistical analysis provided some information on $H_{\mathrm{s}}$ extreme values only, but the wave models need to be forced with wave triplets $\left(H_{\mathrm{s}}, T_{\mathrm{p}}, D_{\mathrm{p}}\right)$ to propagate the wave field nearshore. Different methods can be called on to assign a period and a direction to the extreme values of $H_{\mathrm{s}}$. A first possibility entails performing a regression on bivariate diagrams to calculate simple laws linking $H_{\mathrm{s}}$ with $T_{\mathrm{p}}$, on the one hand, and $H_{\mathrm{s}}$ with $D_{\mathrm{p}}$, on the other. Here, we chose an alternative method that entails using historical events and modifying the $H_{\mathrm{S}}$ values to make them fit the $50-\mathrm{yr} H_{\mathrm{s}}$ without changing the period and direction. For the southern waves, three historical cases were selected to cover the range of possibilities for the direction of origin; for the trade-wind waves, only one 
Table 1. GHMM classification of the NWW3 time series at "Point East" $\left(21^{\circ} \mathrm{S} 56^{\circ} 15^{\prime} \mathrm{E}\right)$. The result obtained for the cyclonic class is a mean of NWW3 model outputs that can be associated to cyclonic waves in the time series. Because of its coarse temporal and spatial resolutions, NWW3 underestimates the cyclonic waves, so that the associated values are not accurate.

\begin{tabular}{|c|c|c|c|c|c|c|c|}
\hline & \multicolumn{3}{|c|}{ Barycenters } & \multirow[t]{2}{*}{$\begin{array}{r}H_{\mathrm{S}} \text { standard } \\
\text { deviation }(\mathrm{m}) \\
\text { within the class }\end{array}$} & \multirow[t]{2}{*}{$\begin{array}{r}T_{\mathrm{p}} \text { standard } \\
\text { deviation (s) } \\
\text { within the class }\end{array}$} & \multirow[t]{2}{*}{$\begin{array}{r}D_{\mathrm{p}} \text { standard } \\
\text { deviation (s) } \\
\text { within the class }\end{array}$} & \multirow[t]{2}{*}{$\begin{array}{r}\text { Relative } \\
\text { occurrence of } \\
\text { the class }(\%)\end{array}$} \\
\hline & $H_{\mathrm{S}}(\mathrm{m})$ & $T_{\mathrm{p}}(\mathrm{s})$ & $D_{\mathrm{p}}\left({ }^{\circ}\right)$ & & & & \\
\hline Cyclones and tropical storms & 2.2 & 7.4 & 112 & 1 & 1 & 68 & 8.4 \\
\hline Trade-wind waves & 2.4 & 9.3 & 115 & 0.6 & 1.6 & 32.3 & 43.5 \\
\hline Southern waves & 2.3 & 12.2 & 199 & 0.7 & 1.9 & 25.3 & 48.1 \\
\hline
\end{tabular}
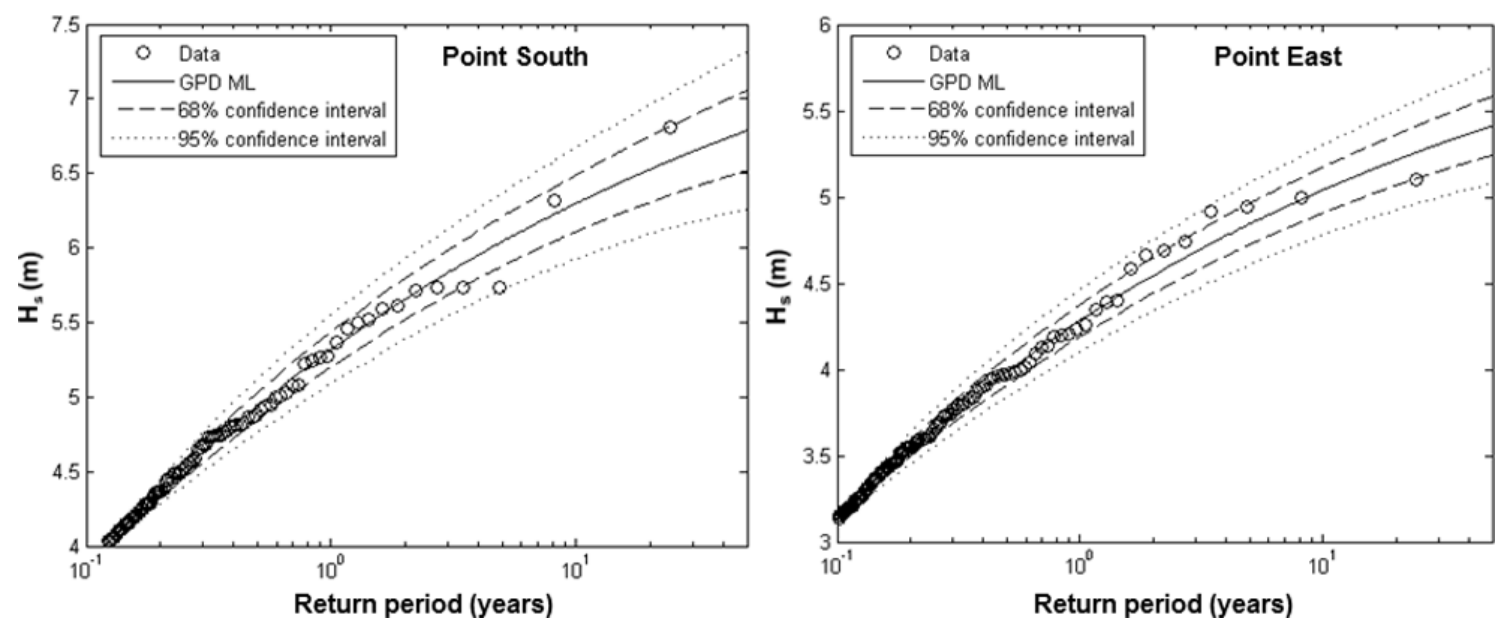

Fig. 4. Return values of $H_{\mathrm{S}}$ for southern waves at "Point South" (left) and trade-wind waves at "Point East" (right) obtained with the POT method and GPD laws. Results are presented up to a return period of $50 \mathrm{yr}$.

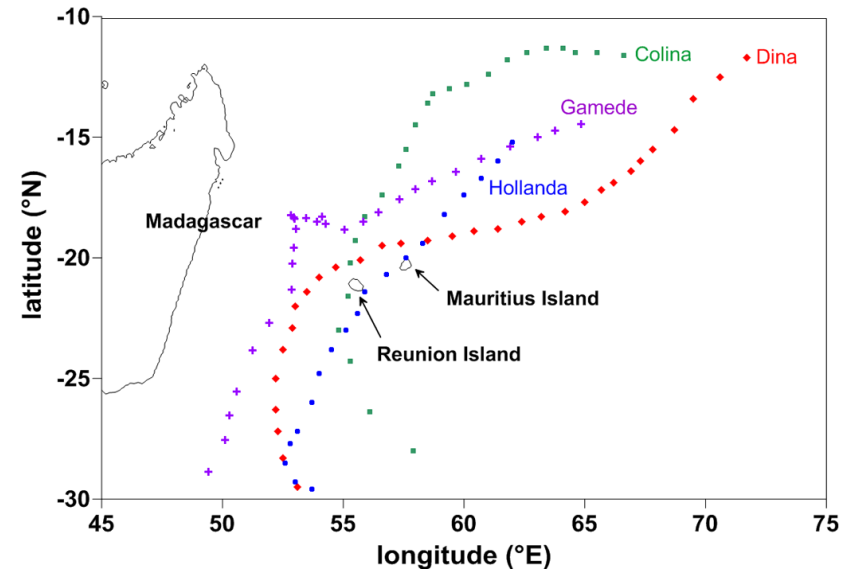

Fig. 5. Tracks of the four cyclones considered in this study: Gamede (purple crosses), Dina (red diamonds), Colina (green squares) and Hollanda (blue dots). case was selected because the range of directions was more limited:

- Case 1 (southern waves): based on the 1 August 2003 event with a southern origin;

- Case 2 (southern waves): based on the 2 August 2003 event coming from the southeast;

- Case 3 (southern waves): based on the 13 May 2007 event coming from the southwest;

- Case 4 (trade-wind waves): based on the 12 July 2006 event, which was the strongest trade-wind wave event with a southeastern origin.

For each case, the wave parameters $\left(H_{\mathrm{s}}, T_{\mathrm{p}}, D_{\mathrm{p}}\right)$ were extracted on the eight NWW3 boundary points surrounding the island (see Fig. 1). Then, the $H_{\mathrm{s}}$ parameter was multiplied by the same coefficient at each of the eight points. For the southern wave cases (Cases 1 to 3 ), this coefficient was calculated in such a way as to ensure that the new $H_{\mathrm{s}}$ was equal to the 50 -yr value at "Point South" (where the statistical analysis was performed). For the trade-wind wave case (Case 4), it 

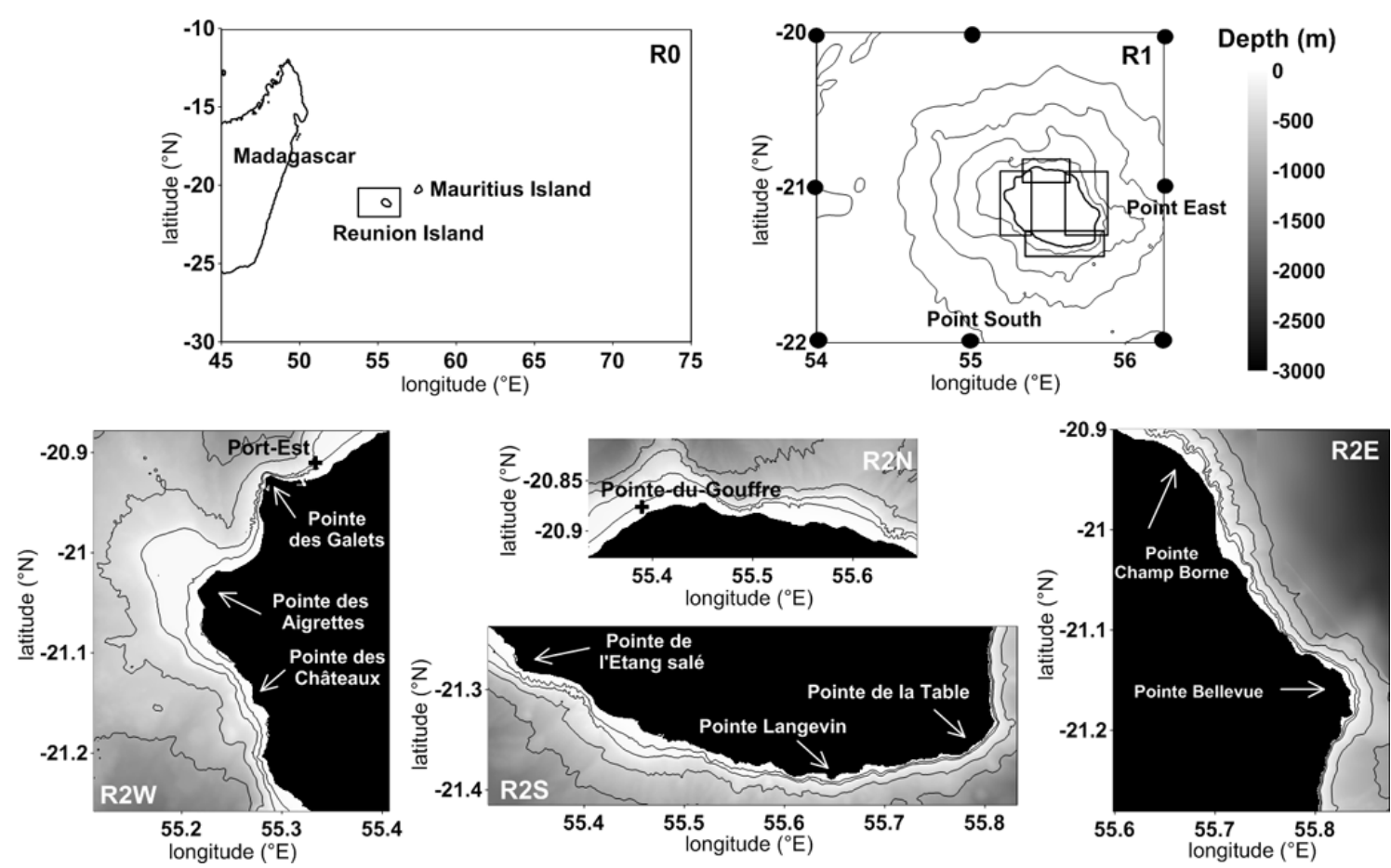

Fig. 6. Nested grids used for the modelling of waves with SWAN.

was calculated so that the 50 -yr value was reached at "Point East". The $T_{\mathrm{p}}$ and $D_{\mathrm{p}}$ parameters were not modified.

\subsection{Determination of the extreme wave scenarios for cyclonic waves}

\subsubsection{Scenario building}

The cyclonic wave scenarios correspond to historical cyclones selected on two criteria: their intensity (greater than category 4 on the Dvorak scale) and their track (very close to the island). We chose three intense cyclones having tracks representative of the different possible configurations, as illustrated in Fig. 5. Dina (January 2002) came from the northeast and passed north of Reunion Island (category 6). Colina (January 1993) came from the north and passed west of Reunion Island (category 4). Hollanda (February 1994) came from the northeast, and it is one of the rare cyclones to have passed south of Reunion Island (category 4). Additionally, cyclone Gamede (February 2007) was used for validation and to complete sensitivity tests because neither offshore nor coastal wave gauges were operational during the three selected cyclones.

\subsubsection{Reconstitution of the wind fields}

The application of wave models to tropical cyclones requires the reconstitution of a 2-D surface wind input over the entire course of the storm. For this study, we used parametric wind models to create the wind fields. The main difficulty when creating cyclonic wind fields is to reproduce the asymmetric structure of the cyclone, which is controlled by many factors, including hurricane motion, environmental conditions, vertical shear and surface friction (Phadke et al., 2003). For the three selected cyclones, the basic parameters (track, maximum wind speed, radius of maximum wind, minimum central pressure) were defined, and for Dina and Hollanda we also had the $30 \mathrm{kt}$ wind radius, which yields information about the cyclone's structure. Two parametric wind field models were used. The first, based on Holland (1980), reproduces symmetric cyclonic wind fields (idealized by concentric circles) with the basic parameters. The second, based on Xie et al. (2006), provides asymmetric cyclonic wind fields. This latter model is a modification of Holland's approach in which the storm's asymmetric structure is depicted by the radial extent of $30 \mathrm{kt}$ winds in the four quadrants (north, east, south, and west). Xie et al. (2006) showed that this approach significantly improves the accuracy of the wind model, but its use is limited by the availability of information about the radial extent of the wind. Thus, for Colina we used the symmetric wind model and for Dina and Hollanda, we used the asymmetric model. The wind fields were gridded at $0.1^{\circ}$ with a time step of $30 \mathrm{~min}$.

\subsection{Wave modelling}

Seven wave scenarios were identified: four modified historical events for non-cyclonic waves (corresponding to a $50-\mathrm{yr} H_{\mathrm{S}}$ return period) and three historical cyclones. For 


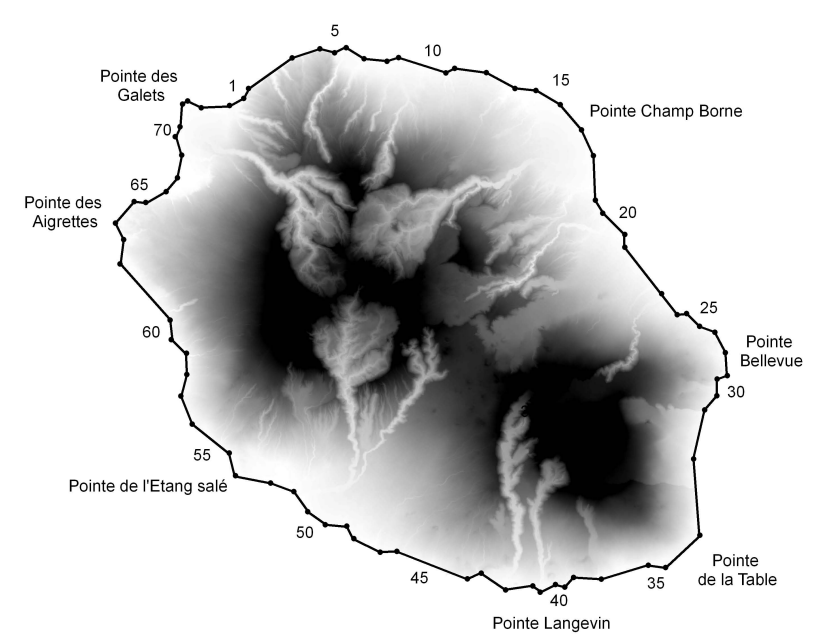

Fig. 7. Positions of the 74 segments into which the Reunion Island coastline has been divided.

each scenario, the nearshore wave fields were simulated with SWAN. This is a third-generation model devoted to the simulation of wave characteristics nearshore, as described in Booij et al. (1999). It solves the spectral action balance equation and takes into account wave generation, propagation, dissipation, and non-linear wave interactions. Figure 6 presents the three nested grid levels defining the model domain. The first grid (R0), covering a large portion of the Indian Ocean, enables the wave fields to be generated with wind forcing alone. The spatial resolution is about $10 \mathrm{~km}$, and the time step is one hour. The second grid (R1), with a $1 \mathrm{~km}$ resolution, is centred on Reunion Island with a computation time step of $30 \mathrm{~min}$. Lastly, four grids (R2N, R2E, $\mathrm{R} 2 \mathrm{~S}, \mathrm{R} 2 \mathrm{~W}$ ) around Reunion Island describe the coastline and the nearshore waters with a resolution of about $100 \mathrm{~m}$ and a computation time step of $30 \mathrm{~min}$.

For the cyclonic scenarios, the simulations were performed in a transitional mode to reproduce the entire course of the cyclones. The wave fields were first generated at grid R0 with the parametric cyclonic wind only. Next, the results were applied as boundary conditions in the nested grids to propagate the wave fields up to the four R2 (second rank) grids. For the non-cyclonic scenarios, the simulations were performed in a stationary mode. First, the wave triplets $\left(H_{\mathrm{s}}\right.$, $T_{\mathrm{p}}, D_{\mathrm{p}}$ ) were propagated in grid R1 by forcing the boundaries with the conditions established in Sect. 3.1.3. Then, the four R2 grids were nested with the results of grid R1.

\subsection{Local comparisons and extreme wave characteristics assessment}

\subsubsection{Segmentation of the coast}

The assessment of local extreme wave characteristics was performed for coastal segments of uniform orientation

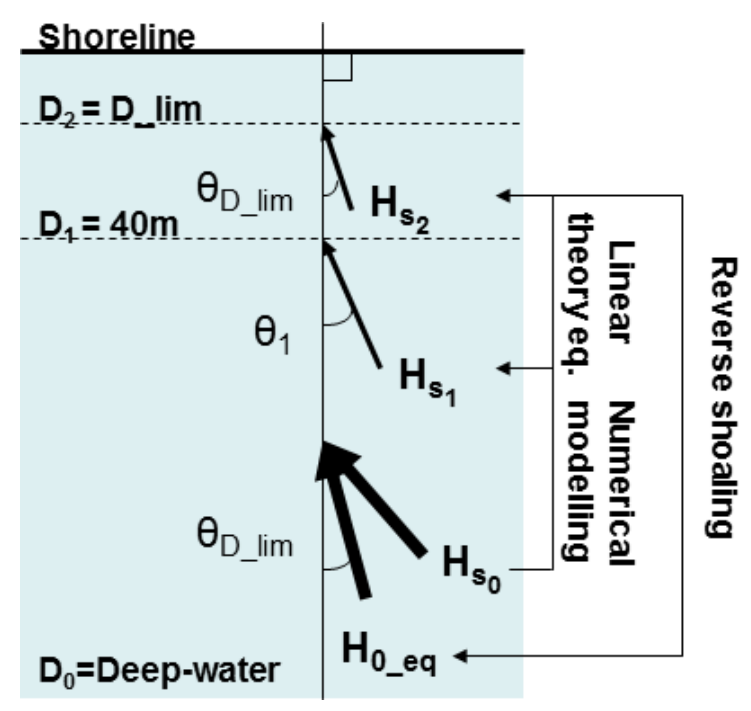

Fig. 8. Description of the process used to determine the equivalent deep-water wave heights $\left(H_{0 \_ \text {eq }}\right)$ from the deep-water wave height of the seven scenarios $\left(H_{\mathrm{s} 0}\right)$ using numerical modelling and linear theory equations (Eq. 2 to Eq. 4 in Sect. 3.4.2).

around the island. The Reunion Island coastline was broken down into 74 segments, as depicted in Fig. 7. A nearshore point on the 40-m isobath was associated with each segment to extract the wave parameters $\left(H_{\mathrm{s}}, T_{\mathrm{p}}, D_{\mathrm{p}}\right)$ from the R2 grids for each scenario and at each computational time step. The choice of the 40-m isobath was motivated by the accuracy of the model nearshore. Indeed, although the resolution of the R2 grids is good (about $100 \mathrm{~m}$ ), the very steep slopes of the bathymetry around the island reduce the sensitivity of the model close to the shore. The model's accuracy for depths of less than $40 \mathrm{~m}$ is expected to be insufficient at a few locations along the coast (especially in the southeast).

\subsubsection{Determination of the equivalent deep-water waves}

The "equivalent deep-water waves" were calculated from the local wave conditions extracted at a $40-\mathrm{m}$ depth with the procedure summarized in Fig. 8. Here, we assume that the wave transformation due to refraction and shoaling follows the linear theory equations and that the depth contours are evenly spaced and parallel to the shoreline. The complete mathematical description is beyond the scope of this study but can be found in Dean and Dalrymple (1991). The basic equations are:

$$
\begin{aligned}
& H_{\mathrm{s}_{2}}=H_{\mathrm{S}_{1}} K_{\mathrm{S}} K_{\mathrm{r}} \text { with } K_{\mathrm{S}}=\sqrt{\frac{C \mathrm{~g}_{1}}{C \mathrm{~g}_{2}}} \text { and } K_{\mathrm{r}}=\sqrt{\frac{\cos \left(\theta_{1}\right)}{\cos \left(\theta_{2}\right)}} \\
& L_{2}=\frac{g T_{2}^{2}}{2 \pi} \tanh \left(\frac{2 \pi d}{L_{2}}\right)
\end{aligned}
$$

where $H_{\mathrm{s}_{1}}$ and $T_{1}$ are the wave height and period at a 40-m depth, and $H_{\mathrm{s}_{2}}, T_{2}$ and $L_{2}$ are, respectively, the wave height, 

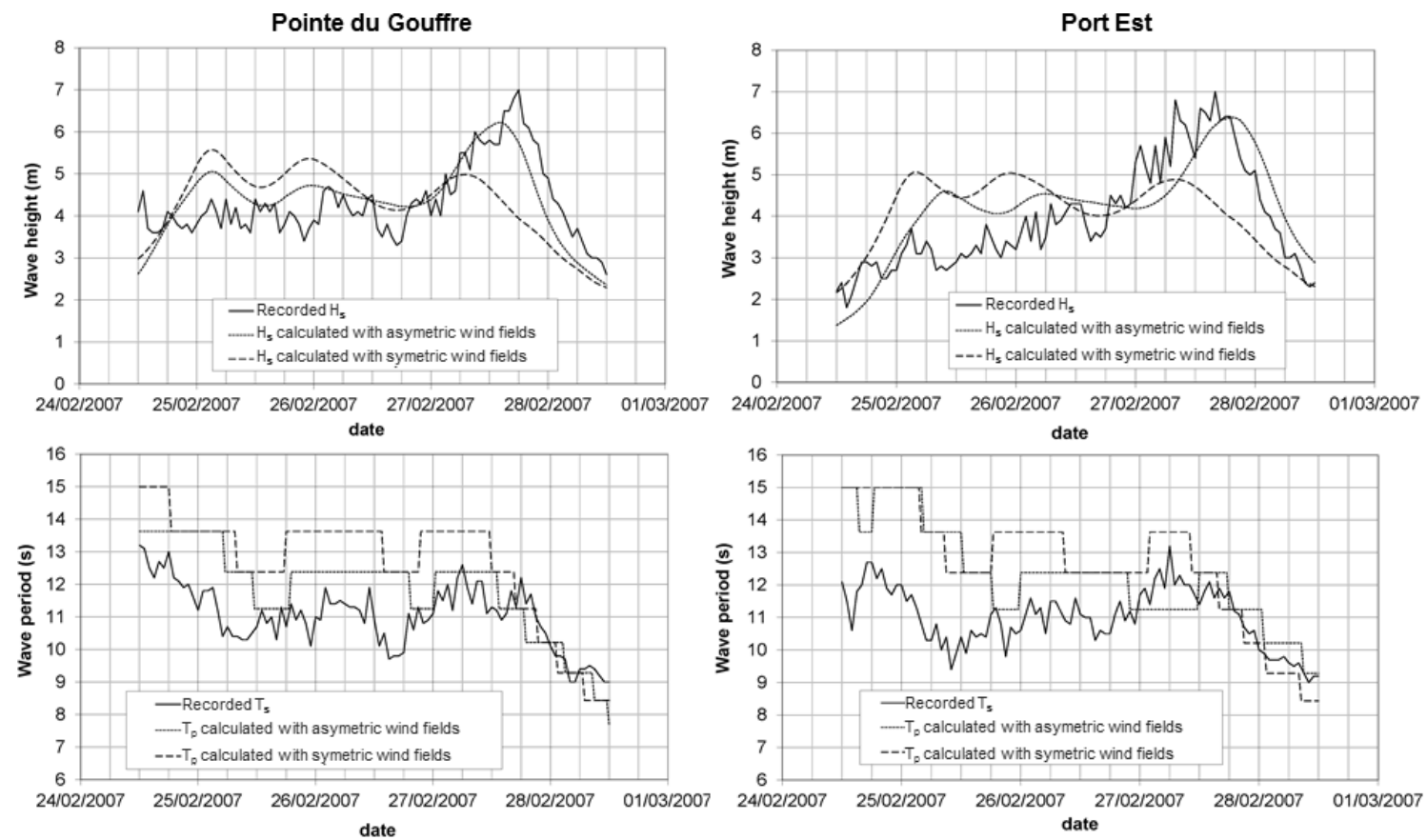

Fig. 9. Comparison between wave heights and periods recorded by the wave gauges at "Pointe du Gouffre" (left) and "Port Est" (right) and the wave parameters calculated with SWAN using the parametric wind fields.

period and wavelength at depth $d . K_{\mathrm{S}}$ and $K_{\mathrm{r}}$ are, respectively, the shoaling coefficient and the refraction coefficient, where $C_{\mathrm{g}}$ is the group velocity and $\theta$ is the angle between the wave crest and the depth contours. Deep-water wavelength $\left(L_{0}\right)$ and period $\left(T_{0}\right)$ are assumed to be interdependent and linked by Eq. (4):

$L_{0}=\frac{g T_{0}^{2}}{2 \pi}$.

The curved shape of island coastlines, with differently oriented sides, implies that waves may not be fully refracted at a 40-m depth, within the model's accuracy limitations. For this reason, the shore-normal approach cannot be directly assumed to back calculate the "equivalent deep-water wave height". Thus, given the initial wave conditions at $40-\mathrm{m}$ depth, the wave parameters were first determined for shallower depths with Eqs. (2) and (3) up to a depth limit calculated as $D_{-} \lim =H_{\mathrm{s}} / 0.7$ (to avoid exceeding the breaking depth). The objective of this first step was to calculate the wave characteristics at very shallow depths, beyond the limit of resolution of the model, in order to approximate the fully refracted wave characteristics and minimize the wave incidence angle. Then, the "equivalent deep-water wave heights" $H_{0 \_ \text {eq }}$ were calculated by dividing the wave heights calculated previously with the shoaling coefficient $K_{\mathrm{s}}$.

\subsubsection{Comparison between the scenarios}

The comparison between the sites and scenarios was based on both the "equivalent deep-water wave heights" $\left(H_{0_{-} \text {eq }}\right)$ and the term $H_{0 \_ \text {eq }}^{2} L_{0}$, which is a good indicator of wave energy.

\section{Results}

\subsection{Cyclonic waves}

\subsubsection{Validation with cyclone Gamede}

The track of cyclone Gamede is plotted in Fig. 5. The wind field was created with both symmetric and asymmetric models described in Sect. 3.2.2. Until 25 February 2007, Gamede's structure remained quite symmetric. Then, the cyclonic motion abruptly changed, thereby inducing asymmetry in the cyclone structure. We compared the $H_{\mathrm{s}}$ computed with both wind fields with the two coastal wave gauges measurements at "Port Est" and "Pointe du Gouffre" when the computed wave heights exceeded $3 \mathrm{~m}$ (see Fig. 9). If asymmetric wind fields are used, the computed $H_{\mathrm{s}}$ is quite comparable to the buoy measurements: the rms difference is $0.63 \mathrm{~m}$ at "Pointe du Gouffre" and $0.9 \mathrm{~m}$ at "Port Est". At the peak of the storm, both wave gauges indicated $H_{\mathrm{s}}$ values of $7 \mathrm{~m}$, while the simulations estimated $6.2 \mathrm{~m}$ at "Pointe du Gouffre" and $6.4 \mathrm{~m}$ at "Port Est". Concerning the wave periods, since measurements of $T_{\mathrm{p}}$ were not available, we compared the computed $T_{\mathrm{p}}$ with the recorded $T_{\mathrm{s}}$ (the average period of the $1 / 3$ highest waves). The ratio of $T_{\mathrm{s}} / T_{\mathrm{p}}$ is approximately equal to 0.93, according to Goda (2000). For both cases, the computed wave periods compare well with the records. 
These tests show that the accuracy of the model with asymmetric parametric wind fields is satisfactory. Using symmetric wind fields produces larger errors when the structure of the cyclone becomes very asymmetric. We used the symmetric model for cyclone Colina only. Considering that it was a slow-moving cyclone with a translation speed of less than $7.5 \mathrm{~m} \mathrm{~s}^{-1}$ and a rather straight track, we assume that the symmetric model still yielded a good representation of the wind field.

\subsubsection{Results of the simulations}

The results of the simulations at grid R1 are shown in Fig. 10 but the following results are extracted from the R2 grids. Dina is the cyclone that generates the most energetic and widespread waves. The waves mainly affect the eastern and the northern sides of the island. They are particularly a threat for the eastern side because they have a shore-normal direction and therefore are very little refracted. At a depth of $40 \mathrm{~m}$, the most energetic waves occur at the "Pointe Champ Borne", with $H_{\mathrm{s}}$ up to $18 \mathrm{~m}$ and $T_{\mathrm{p}}$ about $17 \mathrm{~s}$. Further south, $H_{\mathrm{S}}$ varies between $16 \mathrm{~m}$ and $12 \mathrm{~m}$, depending on the orientation of the coast. On the northern side, the wave angle of incidence is higher, but the waves are still very energetic nearshore. Going from east to west, $H_{\mathrm{s}}$ decreases until $8 \mathrm{~m}$. Cyclone Hollanda is an interesting event because it generates waves coming from the southeast that strongly impact the southern side. From the "Pointe de la Table" to the "Pointe de l'Etang-Salé", $H_{\mathrm{s}}$ decreases from $13 \mathrm{~m}$ to $8 \mathrm{~m}$ with $T_{\mathrm{p}}$ from $14 \mathrm{~s}$ to $12 \mathrm{~s}$ at a $40 \mathrm{~m}$ depth. The waves of cyclone Colina affect only the northern side of the island, with shore-normal waves having $H_{\mathrm{s}}$ values mainly between $10 \mathrm{~m}$ and $12 \mathrm{~m}$ and $T_{\mathrm{p}}$ values around $14 \mathrm{~s}$ at $40 \mathrm{~m}$ depth. None of the three selected cyclones generated important waves on the island's western side.

\subsection{Non-cyclonic waves}

\subsubsection{Validation with the 13 May 2007 southern wave event}

The 13 May 2007 southern wave event particularly affected the western portion of the coast. The R2 simulations displayed good agreement with the measurements of the "Port Ouest" and "Saint Pierre" wave gauges. At "Saint Pierre", the wave gauge measured a maximum $H_{\mathrm{s}}$ of $5.9 \mathrm{~m}$, and the simulation estimated $5.5 \mathrm{~m}$. At "Port Ouest", the maximum measured $H_{\mathrm{s}}$ was $3.9 \mathrm{~m}$, while the simulation gave $3.8 \mathrm{~m}$.

\subsubsection{Results of the simulations}

Figure 10 also shows the results of the simulations at grid R1 for each non-cyclonic scenario. The trade-wind wave scenario (Case 4) is clearly less energetic than the three other southern wave scenarios. Case 3 is the dominant non-cyclonic event, with shore-normal waves impacting the southern side of the island. At a $40 \mathrm{~m}$ depth (on R2 grids), $H_{\mathrm{s}}$ ranges between 5 and $6 \mathrm{~m}$ from the "Pointe de la Table" to the "Pointe des Aigrettes" and $T_{\mathrm{p}}$ reaches $17 \mathrm{~s}$. On the northern side of the island, $H_{\mathrm{s}}$ is very low.

\subsection{Impact of the different wave regimes on the coast}

The objective of the comparison is to determine which zones of Reunion Island will be most severely at risk of setup and runup in cases of extreme events, and with respect to which wave regime.

Figure 11 presents the characteristics of the "equivalent deep-water waves", with the highest $H_{0 \text { eq }}^{2} \times L_{0}$ obtained for each regime with the method described in Sect. 3.4.2. We distinguish three areas of influence:

- On the large half of the island, extending from the northwest to the southeast (clockwise from segment 72 to segment 34), Dina's waves are dominant. $H_{0 \_ \text {eq }}$ reaches a maximum of about $18 \mathrm{~m}$ near the "Pointe Champ Borne" (segment 15). In general, $H_{0 \text { eeq }}$ is higher in the eastern part of the area, with most of the values exceeding $13 \mathrm{~m}$. In the northern part, $H_{0_{-} \text {eq }}$ decreases rapidly down to $6 \mathrm{~m}$ towards the extreme west. $T_{0}$ remains homogeneous in the area, with values of approximately $17 \mathrm{~s}$.

- From the southeast to the southwest (clockwise from segment 34 to segment 53), Hollanda becomes dominant nearshore. Its original track, passing to the southeast of the island, induces the generation of waves from the southeast that are less dissipated than the ones generated by Dina. Even if southern waves have longer periods in this area ( $T_{0}$ up to $17 \mathrm{~s}$ ), the waves of Hollanda remain slightly more energetic, with a maximum $H_{0 \_ \text {eq }}$ of about $13.3 \mathrm{~m}$ at the "Pointe Langevin" (segment 40) and an associated $T_{0}$ of about $14 \mathrm{~s}$. In the remainder of the area, most of the $H_{0_{-} \text {eq }}$ exceed $10 \mathrm{~m}$.

- From the southwest to the northwest (clockwise from segment 54 to segment 71), cyclonic waves and southern waves (Case 3 ) have very similar energies. Indeed, this area is not directly exposed to cyclonic waves, which are very dissipated when reaching the coast, with $H_{0 \_ \text {eq }}$ up to $8 \mathrm{~m}$ but $T_{0}$ not exceeding $12 \mathrm{~s}$. On the other hand, southern waves have a shore-normal incidence, with $H_{0 \_ \text {eq }}$ less than $6 \mathrm{~m}$ but high $T_{0}$ of about $17 \mathrm{~s}$. This area is the one with the lowest energy.

The angles to the shore $(\theta)$ of the initial waves, extracted at a $40-\mathrm{m}$ depth, ranged from $1^{\circ}$ to $70^{\circ}$. When applying the method described in Sect. 3.4.2., the angles at depth D_lim ranged for the most part from $1^{\circ}$ to $30^{\circ}$, depending on the position and the orientation of the segments. A few studies show that for this range of angles, the impact of the wave angle on the amplitude of the setup or runup is either negligible 


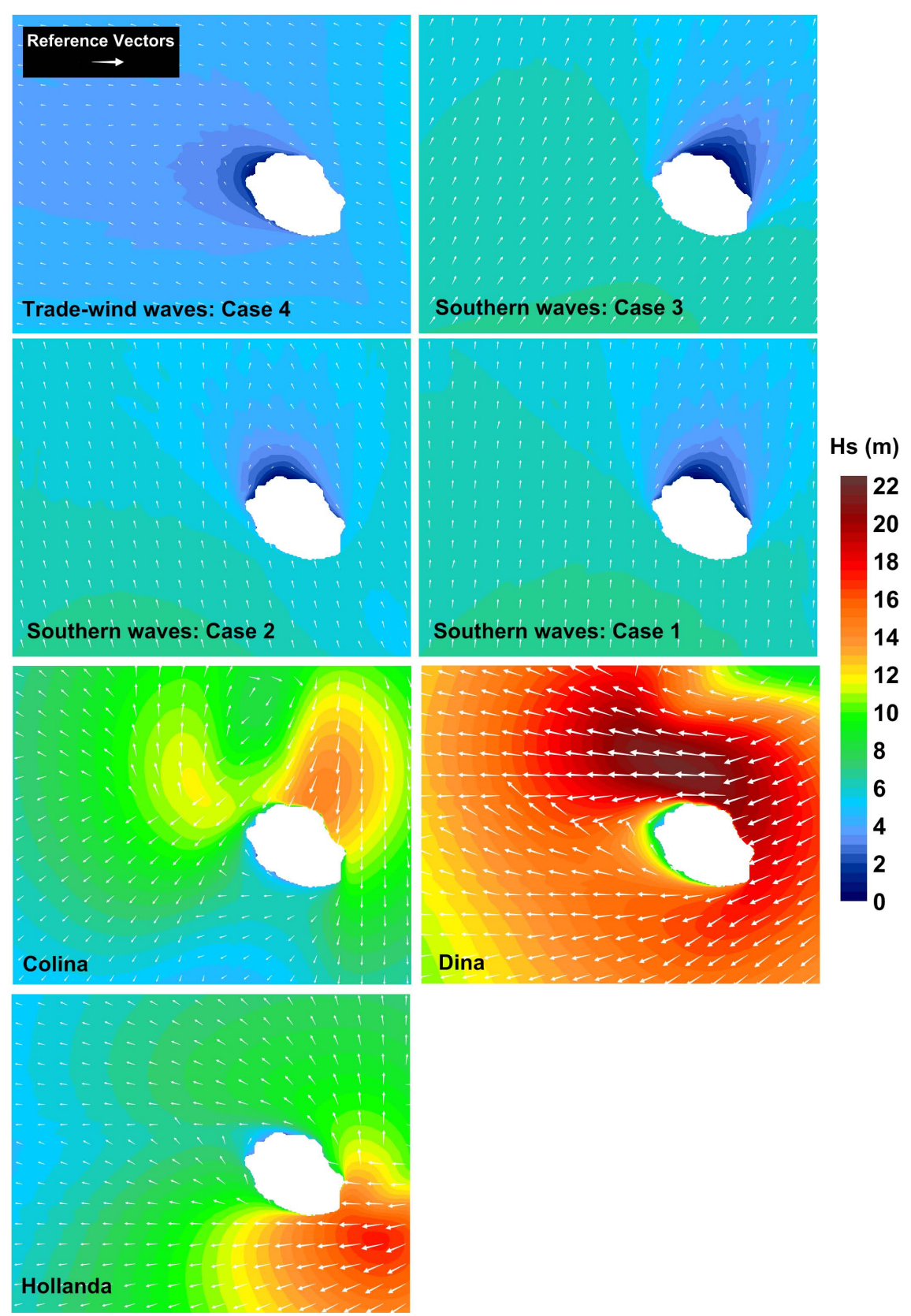

Fig. 10. Wave fields modelled with SWAN for each scenario at grid R1. For the cyclonic scenarios (performed with a transitional mode), the figure corresponds to the peak of the waves near Reunion Island. The colour bar indicates the amplitude of $H_{\mathrm{S}}$ and the vectors indicate wave direction.

or at most minor. As to wave runup at dikes, the report of Van der Meer and Janssen (1995) shows that when $0^{\circ}<\theta<30^{\circ}$, long-crested waves cause almost the same runup as shorenormal waves, with a reduction factor exceeding 0.9. For the wave setup and runup at beaches, little research has been performed. Among the studies that do exist, Hsu et al. (2006) found that the percentage decrease is less than $20 \%$ for incident angles between $0^{\circ}$ and $30^{\circ}$. Thus, with our range of angles, the comparison between the "equivalent deep-water waves" for the different sites and scenarios is relevant in terms of the impact of setup and runup.

\section{Discussion}

This method calls for many steps and concepts which introduce additional levels of uncertainty. The first level is 


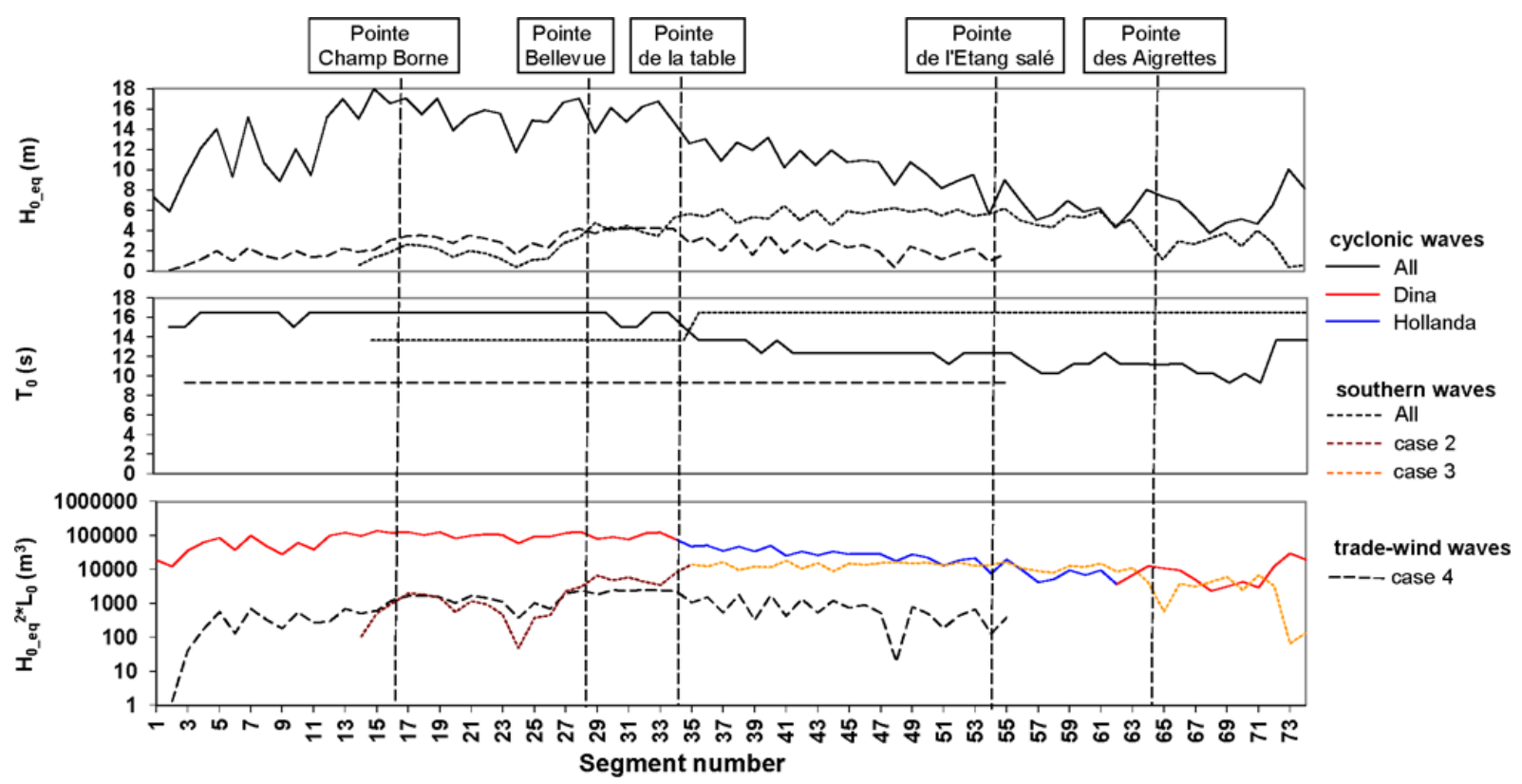

Fig. 11. Characteristics of the most energetic "equivalent deep-water waves" (characterized by the highest $H_{0 \_ \text {eq }}^{2} \times L_{0}$ ) obtained for each regime. In the lowest panel, the scenario producing the most energetic waves within each regime is distinguished.

associated with the data (cyclone best tracks and global wave re-analysis for non-cyclonic waves) and their conversion into wave scenarios. The second level relates to the numerical modelling of nearshore waves (with limitations linked to the simplified representation of physical processes and bathymetric data). The last level is due to the use of linear theory equations to calculate the "equivalent deep-water waves", considering idealized waves and bathymetry. From the authors' points of view, the most important source of uncertainty lies in the first level:

- For non-cyclonic waves, the lack of long-term reanalysis, with a valid representation of extreme waves, remains an obstacle to achieving a reliable analysis of extremes. In this study, the statistical analysis was performed on a 13-yr interval of data and was set to a $50-\mathrm{yr}$ return period. The use of a longer time series would enable the statistical analysis to be extended to the 100 -yr value, which is the one conventionally used in coastal engineering for the design of protective structures. A new re-analysis, with a time coverage expanded to 1988-2011, is currently produced through the IOWAGA project (http://www.ifremer.fr/iowaga). It uses the CFSR dataset (NCEP Climate Forecast System Re-analysis), which is efficient for reproducing extreme events (Saha et al., 2010). The use of such a re-analysis in future work would certainly improve the statistical analysis of non-cyclonic waves.

- For the cyclonic scenarios, we chose to base the analysis on historical cases alone, which were not related to a return period. Statistical approaches exist for calculating the return periods of cyclonic waves. Classically, a synthetic database is first generated with a statistical model, calibrated against a historical dataset in order to enlarge the sample of recorded storms. Then, the wave fields are modelled for each storm in the database, and a statistical analysis is performed on the results to determine the extreme values (James and Mason, 2005; Hardy et al., 2003). This approach is resource intensive because it requires (1) the development of a statistical model representative of a specific cyclonic basin and (2) large computer capacities. This is the reason it was not applied in this study, which aims at presenting a general method. However, the application of the present method with a probabilistic approach for both cyclonic and noncyclonic cases would enable the analysis of the results to be pursued further as it would improve the accuracy of the comparison between the extreme waves from the different regimes.

\section{Conclusions}

A general approach was proposed for determining the extreme wave events that may cause most damage along the various coastlines of tropical islands. It provides local information about extreme waves from each wave regime all around the island and enables (1) inter-comparison of these extremes for a particular location and (2) assessment of the alongshore variability in wave exposition. We think that this method is particularly appropriate for complex environments 
presenting various origins of extreme waves. First, the classification of waves into different regimes enables improvement of the data homogeneity required for the analysis of extremes compared to classical methods using a single criterion such as angular sectors or seasons. Then, this process provides a complete overview of the different kinds of extreme waves that may threaten the coast, which is useful for planners and decision-makers. While cyclonic waves usually cause most reported wave-induced damages, southern and trade-wind waves do disrupt coastal infrastructure or roadmaintenance activities during the Southern Hemisphere winter.

The exposure of each part of the coastline to different categories of extreme events was determined for the pilot site of Reunion Island. Offshore, cyclonic waves appear to be the most energetic waves around the island. However, for the western part of the coast, cyclonic waves are subject to a strong refraction, inducing an important loss of energy nearshore. Thus, non-cyclonic waves with longer periods may finally become as energetic as cyclonic waves when reaching the coast and generate a similar runup.

Our method can be easily implemented for other case studies because it can be adapted depending on the data availability. In this study, we applied this method at a regional scale, using data with a global coverage (global re-analysis, cyclone best tracks, global bathymetric databases, etc.) to provide an overview of extreme waves all around the island. The results obtained with this approach may be used for the mapping of marine submersion hazards by calculating the associated wave setup and runup with empirical formulas. However, the main limitation of this application for tropical islands is the presence of fringing reefs and small bays along some parts of the coast, for which empirical formulas are not adapted. The use of wave-by-wave models able to simulate the full process of runup and submersion may be more suited to this case but requires fine topo-bathymetric data and higher computational capacities. Thus, the assessment of marine submersion maps in this context requires working at higher resolution and adapting the method case by case.

Acknowledgements. We wish to thank Valérie Monbet and Pierre Ailliot for kindly providing the METIS toolbox and for useful recommendations on sea-wave classifications. We are also grateful to Hubert Quetelard from Météo-France (Réunion) for making available the cyclone best-track database and the DDE for providing the buoy measurements. This study was supported by the DREAL La Réunion, and the BRGM research project RISCOTE.

Edited by: S. Tinti

Reviewed by: two anonymous referees

\section{References}

Becker, J. J., Sandwell, D. T., Smith, W. H. F., Braud, J., Binder, B., Depner, J., Fabre, D., Factor, J., Ingalls, S., Kim, S.-H., Ladner, R., Marks, K., Nelson, S., Pharaoh, A., Trimmer, R., Von Rosenberg, J., Wallace, G., and Weatherall, P.: Global Bathymetry and Elevation Data at 30 Arc Seconds Resolution: SRTM30_PLUS, Mar. Geodesy, 32, 4, 355-371, 2009.

Booij, N., Ris, R.C., and Holthuijsen, L.H.: A third-generation wave model for coastal regions, Part I, Model description and validation, J. Geophys. Res., 104, C4, 7649-7666, 1999.

Brodtkorb, P. A., Johannesson, P., Lindgren, G., Rychlik, I., Rydén, J., and Sjö, E.: WAFO - a Matlab toolbox for analysis of random waves and loads, in: Proceeding of the 10th Int. Offshore and Polar Eng. Conf., Seattle, USA, III, 343-350, 2000.

Butel, R., Dupuis, H., and Bonneton, P.: Spatial variability of wave conditions on the French Atlantic coast using in-situ data, J. Coast. Res., 36, 96-108, 2002.

Caires, S., Sterl, A., Bidlot, J. R., Graham, N., and Swail, V.: Intercomparison of different wind-wave reanalyses, J. Climate, 17, 1893-1912, 2004.

Cazes-Duvat, V. and Paskoff, R.: Les littoraux des Mascareignes entre nature et aménagement, L'Harmattan, 186 pp., 2004.

Dean, R. G. and Dalrymple, R. A.: Water wave mechanics for engineers and scientists, Singapore: World Scientific, 2nd Edn., 353 pp., 1991.

Goda, Y.: Random Seas and Design of Maritime Structures, World Scientific, 443 pp., 2000.

Hardy, T. A., McConochie, J. D., and Mason, L. B.: Modeling tropical cyclone wave population of the Great Barrier Reef, J. Waterw. Port. C-Asce, 129, 2, 104-113, 2003.

Holland, G.: An analytic model of the wind and pressure profiles in hurricanes, Mon. Wea. Rev., 108, 1212-1218, 1980.

Hsu, T.-W., Hsu, J.-R.-C., Weng, W.-K., Wang, S.-K., and Ou, S.H.: Wave setup and setdown generated by obliquely incident waves, Coast. Eng., 53, 865-877, 2006.

James, M. and Mason, L.: Generation of a synthetic tropical cyclone database, in: Coasts \$ Ports '99. Challenges and directions for the new century, proceedings of the 14th Australasian Coastal and Ocean Engineering conference and the 7th Australasian Port and Harbour conference, Barton, A.C.T., National committee on Coastal Ocean Engineering, Insitution of Engineers, Australia, 381-386, 1999.

Le Cozannet, G., Lecacheux, S., Delvallee, E., Desramaut, N., Oliveros, C., and Pedreros, R.: Teleconnection Pattern Influence on Sea-Wave Climate in the Bay of Biscay, J. Climate, 24, 641-652, 2011.

Lee, D.-Y. and Jun, K.-C.: Estimation of design wave height for the water around the Korean peninsula, Ocean Sci. J., 41, 4, 245254, 2006.

Mackay, E. B. L., Challenor, P. G., and Bahaj, A. S.: On the use of discrete seasonal and directional models for the estimation of extreme wave conditions, Ocean Eng., 37, 5-6, 425-442, 2010.

Mathiesen, M., Goda, Y., Hawkes, P. J., Mansard, E., Martin, M. J., Peltier, E., Thompson, E. F., and Van Vledder, G.: Recommended practice for extreme wave analysis, J. Hydraul. Res., 32, 6, 803814, 1994.

Menendez, M., Mendez, F.J., Izaguirre, C., Luceno, A., and Losada, I. J.: The influence of seasonality on estimating return values of significant wave height, Coast. Eng., 56, 3, 211-219, 2009. 
Monbet, V. and Aillot, P.: Metocean Time Series (METIS) Toolbox Documentation, Ifremer, 52 pp., available at: http: //www.univ-ubs.fr/adminsite/objetspartages/liste_fichiergw.jsp? OBJET $=$ DOCUMENT \&CODE $=1222201292142 \&$ LANGUE $=$ $1,2005$.

Morton, I. D., Bowers, J., and Mould, G.: Estimating return period wave heights and wind speeds using a seasonal point process model, Coast. Eng., 31, 1-4, 305-326, 1997.

Panigrahi, J. K. and Misra, S. K.: Numerical hindcast of extreme waves, Nat. Hazards, 53, 361-374, 2010.

Phadke, A. C., Martino, C. D., Cheung, K. F., and Houston, S. H.: Modeling of tropical cyclone winds and waves for emergency management, Ocean Eng., 30, 4, 553-578, 2003.

Ruggiero, P., Komar, P. D., McDougal, W. G., Marra, J. J., and Beach R. A.: Wave runup, extreme water levels and the erosion of the properties backing beaches, J. Coast. Res., 17, 407-419, 2001.

Saha, S., Moorthi, S., Pan, H.-L., Wu, X., Wang, J., Nadiga, S., Tripp, P., Kistler, R., Woollen, J., Behringer, D., Liu, H., Stokes, D., Grumbine, R., Gayno, G., Wang, J., Hou, Y.-T., Chuang H.Y., Juang, H.-M. H., Sela, J., Iredell, M., Treadon, R., Kleist, D., Van Delst, P., Keyser, D., Derber, J., Ek, M., Meng, J., Wei, H., Yang R., Lord, S., Van Den Dool, H., Kumar, A., Wang, W., Long, C., Chelliah, M., Xue, Y., Huang, B., Schemm, J.-K., Ebisuzaki, W., Lin, R., Xie, P., Chen, M., Zhou, S., Higgins, W., Zou, C.-Z., Liu, Q., Chen, Y., Han, Y., Cucurull, L., Reynolds, R. W., Rutledge, G., and Goldberg, M.: The NCEP Climate Forecast System Reanalysis, B. Am. Meteor. Soc., 91, 1015-1057, doi:10.1175/2010BAMS3001.1, 2010.
Stockdon, H. F., Holman, R. A., Howd, P. A., and Sallenger Jr., A. H.: Empirical parameterization of setup, swash and runup, Coast. Eng., 53, 573-588, 2006.

Tolman, H. L.: User manual and system documentation of Wavewatch-III version 2.22., NOAA/NWS/NCEP/MMAB Technical Note, 222, 133 pp., 2002.

Van der Meer, J. W. and Janssen, J. P. F. M: Wave run-up and wave overtopping at dikes, in: American Society of Civil Engineers, Wave forces on inclined and vertical wall structures, 1-27, 1995.

Vitousek, S. and Fletcher, C. H.: Maximum annually recurring wave heights in Hawaii, Pacific Sci., 62, 4, 541-553, 2008.

Vitousek, S., Fletcher, C. H., and Barbee, M.: A practical approach to mapping extreme wave inundation: consequences of sea-level rise and coastal erosion, in: Proceedings of Solutions to Coastal Disasters, Oahu, Hawaii, 13-16 April, 85-96, 2008.

Xie, L., Bao, S., Pietrafesa, L. J., Foley, K., and Fuentes, M.: A realtime hurricane surface wind forecasting model: formulation and verification, Mon. Wea. Rev., 134, 1355-1370, 2006. 